\title{
Aqua Recoded - Hyper Hack:usis: Sound and music based on hearing health
}

Luca M. Damiani

University of the Arts London

London, UK

I.damiani@/cc.arts.ac.uk

\author{
Riz Maslen \\ NeoTropic \\ Hastings, UK \\ https://neotropic.net/
}

\section{INTRODUCTION}

Following from my previous works around the topic of hyperacusis, and specifically following my graphic and media design ethnographic exploration of hyperacusis (Damiani 2019) as well as my videopoems (Damiani 2020), here I explore the combination of practices with both visual and sound art, also connecting to sound therapeutic processing via swimming. In this collaborative venture it is all interconnected, and we set-up our band Aqua Recoded (to note: I cannot even listen to music due to my higher sensitivity to sound). In this investigation we wanted to look at the hearing and neuro-otological disorder of hyperacusis with another lens I had not explored yet: creating a music album. This music album is based on sound recording and visual ethnographic processing based on my studies of the condition, using data from sound therapy as well as neurological rehabilitation via swimming and dynamic apnea with underwater sounds. Together with Riz (an experienced electronic musician) we then decided to look into a multi layered piece using my response to the condition and linking it with music via Riz's interpretation.

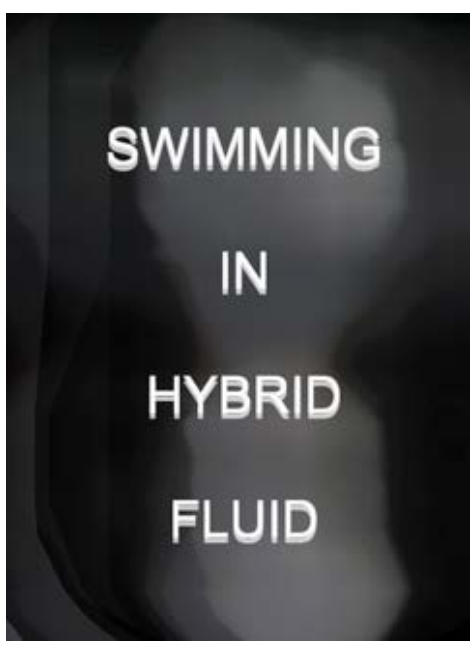

Figure1: Song-Graphic from the album Hyper Hack:usis.

\section{DEVELOPMENT}

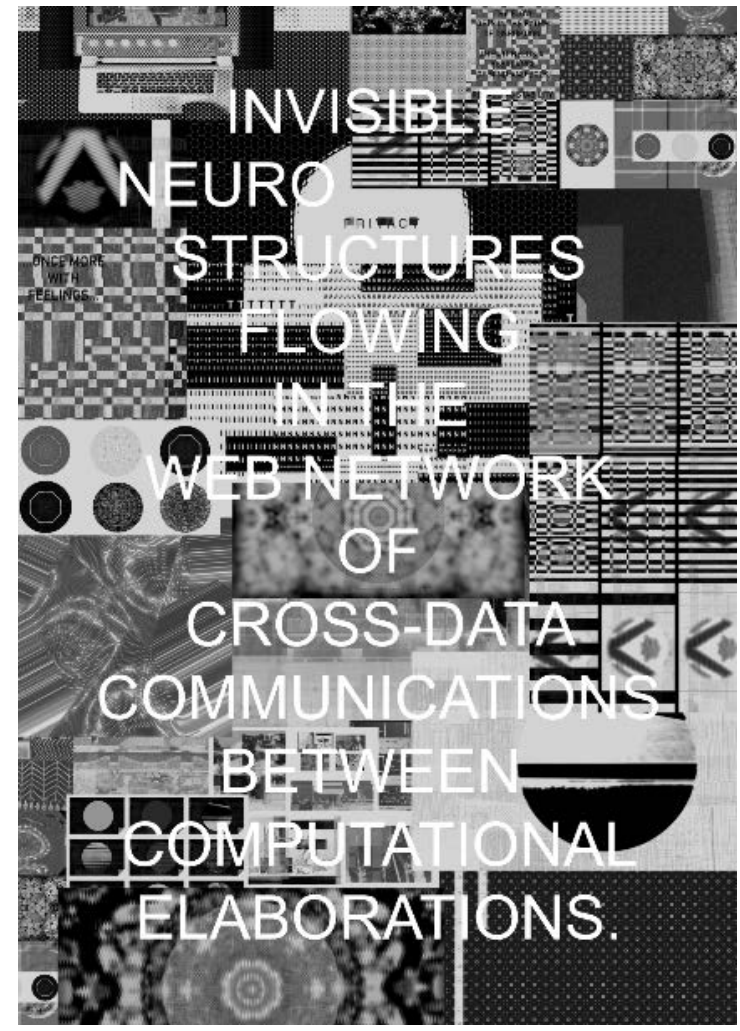

Figure2: Text and graphic response, Luca M Damiani.

As you can see in more details from various of my other art-essays and papers including the one referenced in the Introduction and presented last year at EVA London 2019, I usually take the autoethnographic research data and I visually translate it in computational art. As part of the process I create poems and graphics that express the journey within the sensorial hacked response to the external acoustic stimuli. Within the music and sound art development, the poems become lyrics, the graphics become sounds, and the sound recording of swimming therapy become the base of the music. 


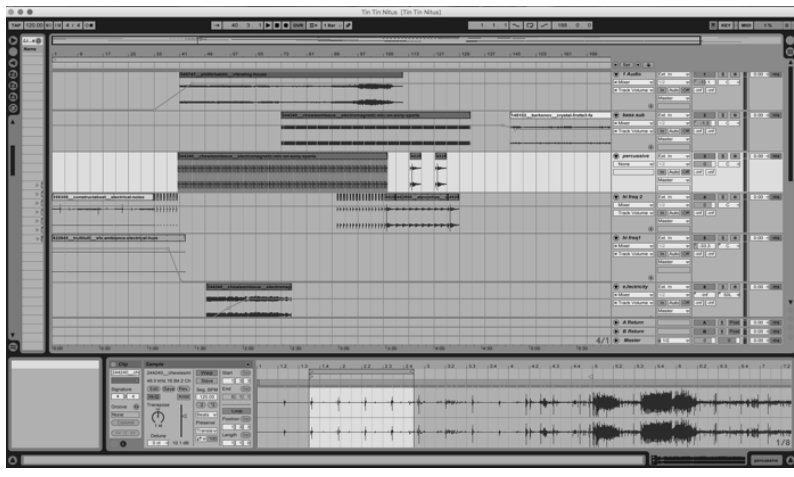

Figure 3: Screenshot of tracks in editing, Riz Maslen.

The music and songs (ten tracks in the whole album) are created and developed in order to form a narrative that follows, explains and translates the neuro-otological disorder, covering: the medical definition, the melt-down of sensory overload, hearing loss, isolation, tinnitus, medication and adaptation. This is an experimental music album that shares the condition with an overall original combination of health, playfulness and media design crossed with sound art. The sound-art response connects to visual work, and it will be shared with a public audience in order to create more awareness on hearing health. In this exploration we then create a piece of music in its own right, and we use tech-installations and digital performances to present it.

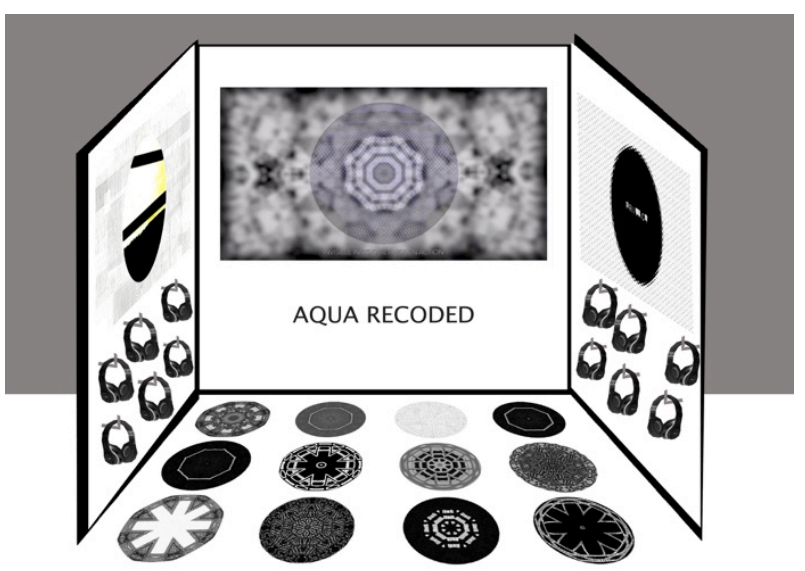

Figure 4: Sound and video-art installation sketch.

\section{OUTPUT}

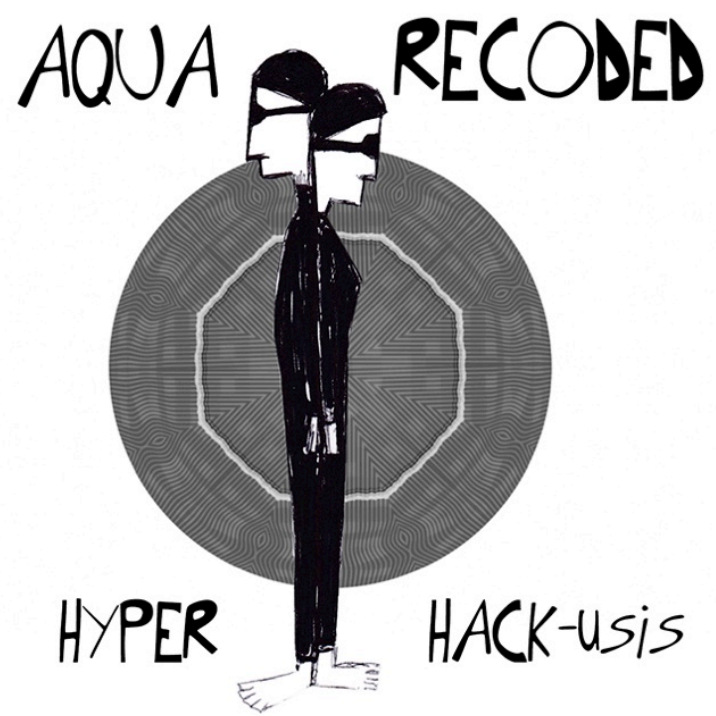

Figure 5: Aqua Recoded album cover.

The Aqua Recoded Hyper Hack:usis (2020) album creates a narrative with ten different songs; it is an engaging piece of artistic, technological and scientific interpretation. Please listen to the full album, we hope you will like it!

\section{REFERENCES}

Aqua Recoded (2020) Hyper Hack:usis. https://aquarecoded.bandcamp.com/

Damiani L. (2019) Hyperacusis Hacks - Media Design Ethnographic Processing, EVA London 2019 (Electronic Visualisation and the Arts).

Damiani L. (2020) Processing Auditory Processing - Hearing Health Foundation. https://hearinghealthfoundation.org/luca-damiani 